\title{
MICROCLONAL PROPAGATION OF CRATAEGUS MONOGYNA JACQ. IN VITRO Nana Zarnadze ${ }^{1}$, Ketevan Dolidze ${ }^{2}$, Sophiko Manjgaladze ${ }^{3}$, Nazi Turmanidze ${ }^{4}$, Jana Chitanava $^{5}$, Gia Bolkvadze $^{6}$, Eteri Jakeli $^{7}$
}

\begin{abstract}
We have researched Crataegus Monogina Jacq. microclonal propagation and in vitro mass regeneration processes. For this experiment we used the asleep buds isolated from maternal plants and in vitro cultivated apical and axillary buds as the effective explants.

The high coefficient of micropropagation was provided with Gamborg Medium (B5) nutrient medium added alongside the hormones of cytokinin nature. The best result was achieved in the case of introduction of 2-Isopentenyladenine (2-iP) at concentration of $5-10 \mathrm{mcm}$ and Benzilaminopurine (BAP) at concentration of $10-15 \mathrm{mcm}$. For stimulation of the mictropropagation process it is reasonable to add a small dose of the auxin hormone 1-Naphtylacetic acid (NAA) together with the cytokinins to the nutritive medium. It has been shown that the growth of micropropagation coefficient in pro rata the kinds and concentration of phytohormones. Regenerated microshoots had a good capacity of rooting. The most effective method for rooting purpose was the introduction of Indole- 3 -butyric acid (IBA) at concentration of 5mcm into $1 / 2$ B5 nutrient medium. The rooted regenerant plants successfully adopted in vivo.
\end{abstract}

UDC Classification: 57.01, DOI: 10.12955/cbup.v7.1494

Keywords: In Vitro Culture; Proliferation; Plant regeneration; Micropropagation; Phytohormones; Adventive buds;

\section{Introduction}

Totipotency of vegetative cell as well as plasticity of vegetative organs and tissues cause high reproductive capacity of plants. This property of vegetable organisms and feasibility of its use in practice allow scientists to develop technology of in vitro cultivation of vegetable organs, tissues and cells. In vitro technology is often used to increase the effectiveness of a selection process. One of its actual aspects includes accelerated propagation of newly produced varieties or isolated plants through microcloning.

Micropropagation of plants in tissue culture includes three stages (Butenko, 1964; Kataeva and Avetisov, 1981; Kataeva and Butenko, 1983):

$1^{\text {st }}$ stage - explanting of the initial plant tissue and further introduction into culture;

$2^{\text {nd }}$ stage - microclonal multiplication: optimal formation of the organs from meristema, their development and propagation;

$3^{\text {rd }}$ stage - preparation of plants for replantation including rootage of the received regenerant plant and acclimatization of the reproduced plants in vitro, i.e. preparation for replantation into soil.

The aim of our research included examination of influence of the trophic factors and growth regulators on in an vitro culture of Crataegus Monogyna Jacq. on the stage of multiplication and receipt of regenerant plants in vivo acclimatized.

According to the scientific writings, various scientists have researched the matters of the various species of hawthorn microclonal propagation (Iapichino and Airo, 2009; Wowtosh et al., 2007; Dai et al., 2007). These authors use the apical and auxiliary meristema (Caboni et al., 2010) or single-bud segments of the lignified shoot (Gökbunar, 2007) as the explants. But some authors prefer leaf segments (Dai et al., 2007). The realization and effectiveness of morphogenetic potential of each explant depends on mineral and hormonal content of the nutrient medium.

\section{Research Material and Methodology}

a) Research object: In our experiment we used Crataegus monogyna Lacq, a medicative plant spread in Georgia, namely in the Batumi Botanical Garden.

b) Methodology: Our experiment aims included induction and optimization of microclonal propagation in vitro under the effect of the nutrients and growth regulators, production of acclimatized regenerant

\footnotetext{
${ }^{1}$ Batumi Shota Rustaveli State University, Batumi, Georgia; z_nana@mail.ru

${ }^{2}$ Batumi Shota Rustaveli State University, Batumi, Georgia; ketodolidze@yahoo.com

${ }^{3}$ Batumi Shota Rustaveli State University, Batumi, Georgia; s.manjgaladze.777@ gmail.com

${ }^{4}$ Batumi Shota Rustaveli State University, Batumi, Georgia; turmanidze.nazi@bsu.edu.ge

${ }^{5}$ Batumi Shota Rustaveli State University, Batumi, Georgia; zhana.tchitanava@gmail.com

${ }^{6}$ Batumi Shota Rustaveli State University, Batumi, Georgia; giabatumi@yahoo.com

${ }^{7}$ Batumi Shota Rustaveli State University, Batumi, Georgia; jakelieteri@gmail.com
} 
plant in vivo. Explant was presented by the vegetating shoots with the asleep buds isolated from the maternal plant. To aim production of the aseptic cultures we used mercuric chloride $0.1 \%$ solution as a sterilizing agent. We inoculated the cultures on the Gamborg $\mathrm{B}_{5}$ (Gamborg et al., 1968) and MS (Murashige and Skoog, 1962) medium, $\mathrm{pH}=5.6-5.8$; nutrient medium was sterilized under 0.9-1 \pm 0.1 atmospheric pressure for 20 minutes. The culture incubation for induction of organogenesis was provided by the light ( $3 \mathrm{kLux}, 16 / 8$ hours photoperiod, temperature $-25 \pm 1 \mathrm{C}$, relative humidity of air $70 \%)$.

We researched the effect of the growth regulators: cytokinins (BAP; 2-iP- 5; 10; 15; $20 \mu \mathrm{m}$ ) and auxins (NAA - $0.5-3 \mu \mathrm{m}$; IBA $-5 \mu \mathrm{m}$ ) of various concentration. The experiment lasted 20 months. In each variant the experiments were provided with a tenfold repetition. Rootage of the explants was provided on the nutrient medium which contained indole acetic acid at 3-5 $\mu \mathrm{m}$ concentration. Acclimatization was provided in the greenhouses in conditions of gradual reducing of high humidity.

\section{Results and Discussion}

Sterilization of explants: The research results proved that the use of $0.1 \%$ mercuric chloride as a sterilized agent with $15 \mathrm{~min}$. exposition caused receipt of maximum quantity of the aseptic cultures $(92.32 \%)$. Chemical necrosis occurred in $5 \%$ of the sowed cultures, but $3 \%$ of them lightly vitrified. These cultures were eliminated from the experiment.

Optimization of multiplication: After receipt of the sterile cultures, at the first stage of multiplication it is important to match the proper mineral balance of nutrition. The scientists use nutrient mediums of the various mineral content for cultivation of hawthorn explants. Most of them prefer Murashige and Skoog Medium (Dai et al., 2007; Maharic et al., 2009; Iapichino and Airo, 2009). Some of them use WPM, DKW and NRM mediums (Nas et al., 2012). Crataegus Azarolus L. is propagated on the modified LP nutrient medium (Caboni et al., 2010). According to the scientific writings, Gamborg nutrient medium almost is not used for induction and optimization of hawthorn morphogenesis. The experiments prove that the mineral content of the Gamborg nutrient medium is very effective for in vitro cultivation of various plants (Lomtatidze et al., 2009; Zarnadze et al., 2018; Zarnadze et.al, 2019). As our experiments showed, Gamborg (Gamborg et al., 1968) and MS (Murashige and Skoog, 1962) nutrient mediums had the effect on the development of micro shoots and initiation of new growths, but in the case of the Gamborg nutrient medium the organogenesis indexes were higher, shoots more intensively grew and developed and the quantity of regenerated new growths during one subcultivation was $12.2 \pm 0.92$ initials. (Table 1).

Effectiveness of the stage of microclonal multiplication is determined with mass induction and regeneration of microshoots. This process is mainly regulated with phytohormones. It is proven with the results of the various scientists' research where the importance of exogenous cytokinins in the process of stimulation and induction of morphogenesis is apparent (Gbadamosi and Egunyomi, 2010; Rajoriya et al., 2018; Siddique et al., 2013). Single-bud microshoots of hawthorn showed mobile dependence on classes and concentrations of phytohormones. The scientists working with the various plants point to the necessity of hormones (Aragão et al., 2017; Mahoney et al., 2018; Stevens and Pijut, 2018).

\begin{tabular}{|c|c|c|c|c|}
\hline \multicolumn{6}{|c|}{ Table 1: Morphogenesis of microshoots on the nutrient mediums of various content } \\
\hline Nutrient medium & $\begin{array}{c}\text { Total quantity of } \\
\text { explants }\end{array}$ & $\begin{array}{c}\text { Average height of } \\
\text { shoots (mm) }\end{array}$ & $\begin{array}{c}\text { Average quantity } \\
\text { of nodal segments }\end{array}$ & $\begin{array}{c}\text { Quantity of } \\
\text { regenerated shoots (\%) }\end{array}$ \\
\hline $\begin{array}{c}\text { Gamborg (B } \\
\text { (2-iP } 5 \text { mcm) }\end{array}$ & 50 & $8.90 \pm 0.93$ & 5.20 & $12.2 \pm 0.92$ \\
\hline $\begin{array}{c}\text { MS } \\
(2-i P 5 \text { mcm) }\end{array}$ & 50 & $8.40 \pm 0.98$ & 4.70 & $11.4 \pm 1.02$ \\
\hline Source: Author & & & \\
\hline
\end{tabular}

Development of buds from microshoots on nutrient medium free of hormones was not practically fixed. Only one or two isolated buds developed with further prolongation of the period of subcultivation required for their normal growth and development. Use of various concentrations of cytokinins showed the various forms of manifestation of totipotency of buds (Table 2). Initiation of shoots from single-bud cuttings and their growth and development, i.e. apical dominance was achieved at low concentration of 2-iP. In the period of the first subcultivation we received good results in the case of the nutrient medium containing 2-iP at a concentration of $5 \mathrm{mcm}$ : for initiation and development of shoots 3-4 weeks were 
enough, the shoots developed on average 7 nodal segments. In the case of the nutrient medium with BAP at a concentration of $5 \mathrm{mcm}$, the period of development of shoots was comparatively longer (5-6 weeks). It should be noted that the increase of BAP concentration up to $10 \mathrm{mcm}$ made the regeneration period considerably shorter and it equaled the effect which occurred in the case of the 2-iP at $5 \mathrm{mcm}$ concentration. The increase of concentration of $2-\mathrm{iP}$ to $10 \mathrm{mcm}$ was concurrent with apical dominance, several growth cones (5-6 initials) developed simultaneously from each axillary bud of the initial explants. They have the same growth rate. At the end of subcultivation period $\left(25^{\text {th }}\right.$ day) the shoots achieved an average height of $30 \mathrm{~mm}$ and missing the stage of compete growing we removed them to a nutrient medium for rootage or for the next stage of mass reproduction on the new nutrition medium of the same content.

The explants had the various morphogenetic response to change of concentration of cytokinins (Table 2). So called adventive buds originated at all tested concentrations of 2-iP and BAP. The regeneration coefficient and buds development model changed concurrently with change in concentration. The results of the low concentrations is described here above. An increase of concentration of phytohormones caused gradual transition to mass budding. 2-iP at concentration of $15 \mathrm{mcm}$ caused apical growth of the main bud. In the majority of cases from the main explants simultaneously several buds developed with proliferation of callus in the basal part. Callus tissue had a nodal structure, where in the process of redifferentiation morphogenetic areas originated from which the adventive buds regenerated in the further period of subcultivation. Their quantity grew pro rata the number of subcultivations. This process lasted up to the completion of the process of proliferation of callus tissue. In the $5^{\text {th }}$ subcultivation the explants became so tightly covered with the regenerated buds, that it restrained proliferation of the basal morphogenetic callus tissue (Fig. 1). The Effect of BAP rather dropped behind the effect of 2-iP. Before rooting we moved the adventive buds of 10-12 mm length to the nutrient medium containing cytokinins at minimum concentration of $3 \mathrm{mcm}$ or the corresponding medium for the new cycle of propagation.

Rise of concentrations of 2-iP and BAP up to $20 \mathrm{mcm}$ showed that $94-98 \%$ of the explants demonstrated maximum potential of mass regeneration (Table 2). On the explants, lots of buds originated simultaneously and all of them were almost of the same dimensions (Fig. 1).

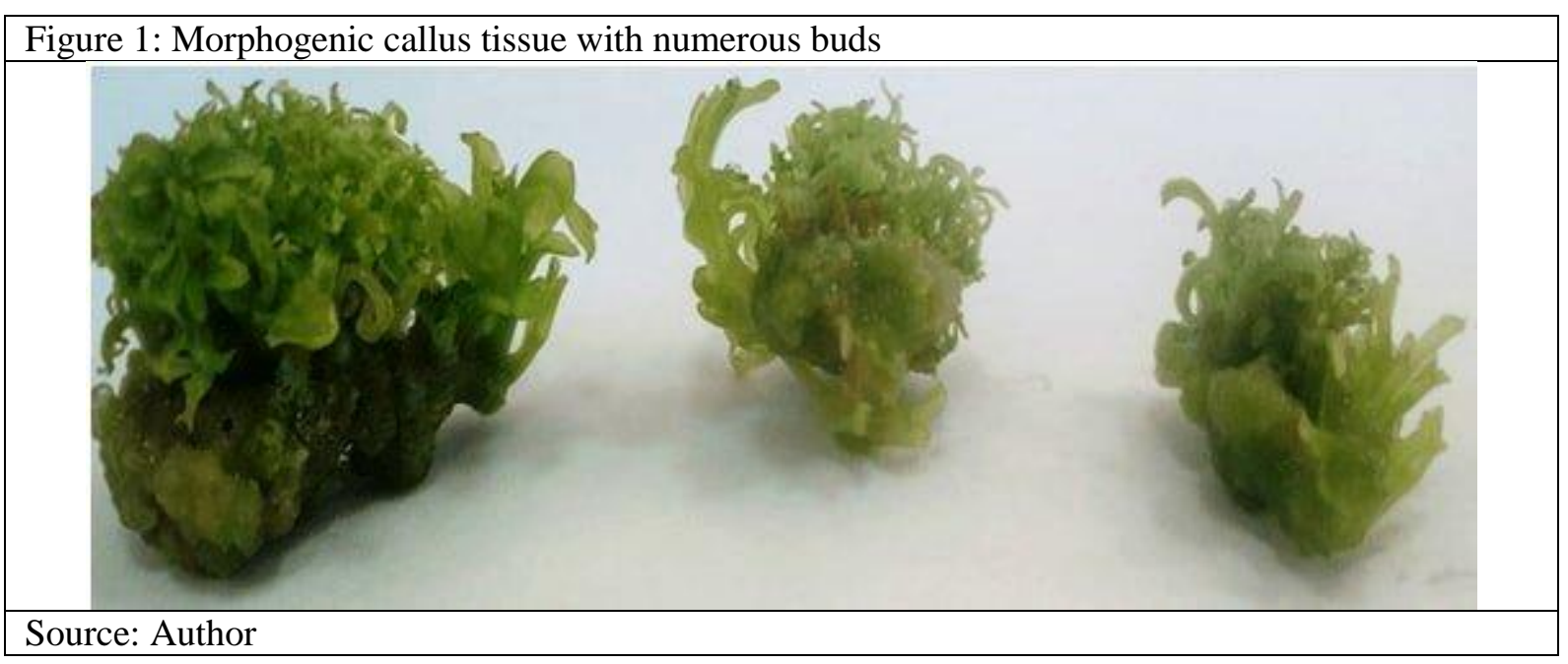

The effect of 15-20 mcm concentrations of BAP and 2-iP strengthened upon introduction of the small dose of NAA into the nutrient medium. As Table 2 shows, the regenerant coefficient grew considerably, which was caused through the induction and intensive proliferation of callus. In the process of bud regeneration, curtain regularity was apparent: all over the surface of callus originated in the basal part of the maternal explants several tens buds regenerated simultaneously. These buds synchronically grew and to the end of subcultivation they were of the same sizes having an equal growth rate and similar morphology (Fig. 1). They may be conditionally named "the first generation" regenerants. After removal of the regenerated buds and moving to the new nutrient medium the "second generation" regenerants synchronically arose on the callus etc. Alteration of generations was observed concurrently with subcultivations up to exhaustion of the morphogenetic potential of the callus. In total we detected four stages of arising of generations from callus tissue, but it should be noted here that $80-85 \%$ of the 
regenerated buds required preparation for rootage, i.e. "growth stage" on the nutrient medium containing a minimum concentration of cytokinin $(3 \mathrm{mcm})$ and auxin at concentration of $0.5 \mathrm{mcm}$ (Fig. 2).
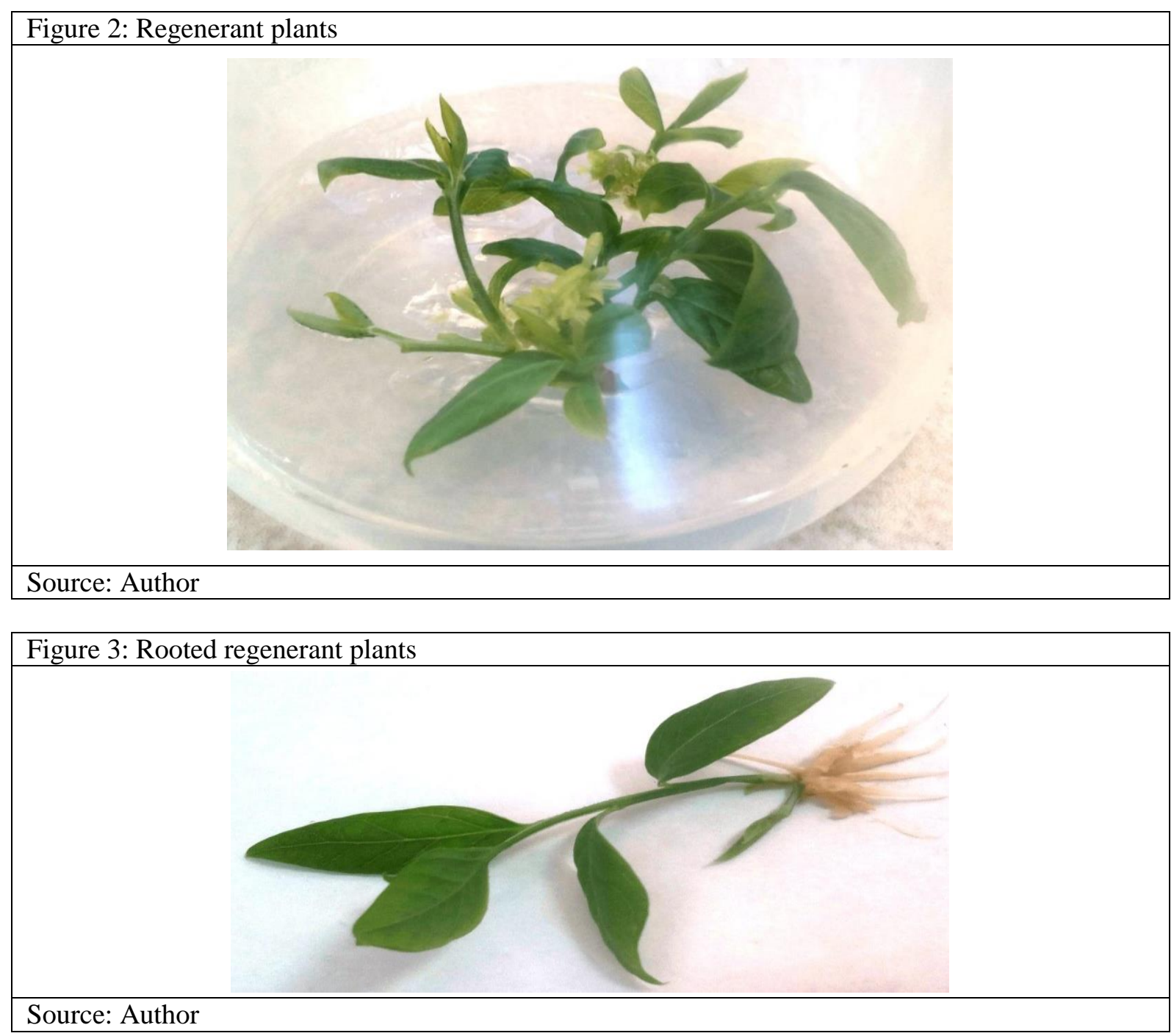

\begin{tabular}{|c|c|c|c|c|}
\hline $\begin{array}{c}\mathrm{B}_{5}+2-\mathrm{iP} \\
(\mathrm{mcm})\end{array}$ & $\begin{array}{l}\text { Q-ty of explants } \\
\text { giving rise to } \\
\text { shoots }(\%)\end{array}$ & $\begin{array}{l}\text { Average length of } \\
\text { shoots, mm }\end{array}$ & $\begin{array}{c}\text { Average q-ty of } \\
\text { nodal segments per } \\
\text { shoot }\end{array}$ & $\begin{array}{c}\text { Average q-ty of } \\
\text { adventive buds per } \\
\text { explant }\end{array}$ \\
\hline (control) & 15.0 & $6.00 \pm 0.90$ & 1.00 & - \\
\hline 5.00 & 62.2 & $20.0 \pm 0.30$ & 7.00 & $5.00 \pm 0.90$ \\
\hline 10.0 & 95.1 & $16.0 \pm 0.40$ & 5.00 & $8.00 \pm 0.80$ \\
\hline 15.0 & 94.0 & $14.0 \pm 0.50$ & 3.00 & $15.0 \pm 0.50$ \\
\hline 20.0 & 98.0 & $9.0 \pm 0.60$ & 2.00 & $23.0 \pm 0.40$ \\
\hline $15.0+\mathrm{NAA} 3 \mathrm{mcm}$ & 98.0 & $8.6 \pm 0.50$ & 1.80 & $32.0 \pm 0.35$ \\
\hline $20.0+\mathrm{NAA} 3 \mathrm{mcm}$ & 98.0 & $7.20 \pm 0.6$ & 1.50 & $38.0 \pm 0.26$ \\
\hline \multicolumn{5}{|l|}{$\begin{array}{c}\mathrm{B}_{5}+\mathrm{BAP} \\
(\mathrm{mcm})\end{array}$} \\
\hline 5.0 & 60.5 & $18.0 \pm 0.31$ & 6.00 & $4.00 \pm 0.90$ \\
\hline 10.0 & 93.1 & $15.0 \pm 0.42$ & 5.00 & $6.00 \pm 0.94$ \\
\hline 15.0 & 93.0 & $12.0 \pm 0.54$ & 3.00 & $13.0 \pm 0.50$ \\
\hline 20.0 & 95.0 & $8.0 \pm 0.64$ & 2.00 & $19.0 \pm 0.50$ \\
\hline $15.0+\mathrm{NAA} 3 \mathrm{mcm}$ & 96.0 & $7.50 \pm 0.61$ & 2.00 & $28.0 \pm 0.40$ \\
\hline $20.0+\mathrm{NAA} 3 \mathrm{mcm}$ & 96.0 & $7.00 \pm 0.60$ & 2.00 & $34.0 \pm 0.34$ \\
\hline
\end{tabular}


Rootage, as the last stage of in vitro micropropagation, was provided:

1) on the Gamborg (B5) nutrient medium + 5 mcm IBA;

2) $1 / 2$ Gamborg (B5) nutrient medium $+5 \mathrm{mcm}$ IBA.

The experiment results showed that rootage occurred on both nutrient mediums, but the better result was received on the second one. The rootlets originated during 3-4 weeks, 94\% of cultures rooted, the rootlets were lanate and ramified (Fig. 3). Total length of rootlets was $15-21 \mathrm{~cm}$ and $86 \%$ of the regenerant plants were acclimatized.

\section{Conclusion}

Our experiments showed the feasibility of successful use of tissues, cells and organs in an in vitro method for microclonal propagation and production of mass regenerants of hawthorn. The important moments include the optimization of total balance of research object, sterilization algorithm and the components and phytohormones of the nutrient medium

\section{References}

Aragão V. P. M., Navarro B.V., Tardin da Silva A., Silveira V., Claudete S. (2017). Micropropagation of Cariniana legalis (Martius) O. Kuntze, an endangered hardwood tree from the Brazilian Atlantic Forest. Plant Cell Culture \& Micropropagation, 13(2), 41-50 pp. http://177.105.2.193/ojs/index.php/PlantCellCultureMicropropagation/article/view/116 Butenko R.G. (1964). Plant Tissue Culture and Plant Biotechnology. (Russian). On default correlation: a copula function approach. (Working Paper of RiskMetrics Group). https://search.rsl.ru/ru/record/01000785993

Caboni E., Meneghini M., Tonelli M. (2010). Improved micropropagation of Azarole (Crataegus azarolus L.). Propagation of Ornamental Plants, 10(1), 9-13 pp. https://www.journal-pop.org/2010_10_1_9-13.html

Dai H., Zhang Z., Guo X. (2007). Adventitious Bud Regeneration from Leaf and Cotyledon Explants of Chinese Hawthorn (Crataegus Pinnatifida Bge. Var. major N.E.Br.). In Vitro Cellular \& Developmental Biology-Plant, 43(1), 2-8 pp. https://link.springer.com/article/10.1007/s11627-006-9008-3

Gamborg O. L., Miller R. A., Ojima K. (1968). Nutrient Requirements of Suspension Cultures of Soybean Root Cells. Exp. Cell Res, 1968, 50: 151-158. https://doi.org/10.1016/0014-4827(68)90403-5

Gbadamosi I. T., Egunyomi A. (2010). Micropropagation of Plumbago zeylanica L. (Plumbaginaceae) in Ibadan, Southwestern. Journal of Medicinal Plants Research, 4(4), 293-297. https://academicjournals.org/journal/JMPR/articleabstract/84DD44715458

Gökbunar L. (2007). in vitro micropropagation of hawthorn (Crataegus sp.) (Master's thesis). Sutcu Imam University, Kahramanmaras, Turkey. http://agris.fao.org/agris-search/search.do?recordID=TR2011000476

Iapichino G., Airò M. (2009). Multiplication of Crataegus Monogina by in Vitro Culture of Nodal Segmentes. ISHS Acta Horticulturae 812: III International Symposium on Acclimatization and Establishment of Micropropagated Plants, 812: 135140. https://doi.org/10.17660/ActaHortic.2009.812.13

Kataeva N.V., Avetisov V.A. (1981). Clonal reproduction in tissue culture. Culture of plant cells. M.: Science,. (Russian). On default correlation: a copula function approach. (Working Paper of RiskMetrics Group), 137-149.

http://agris.fao.org/agris-search/search.do?recordID=US201302632428

Kataeva N.V., Butenko R.G. (1983). Clonal micropropagation of plants. Science: M. (Russian) . On default correlation: a copula function approach. (Working Paper of RiskMetrics Group), 96. http://nonidar.ru/kniga-kataeva-n-v-butenko-r-gklonalnoe-mikrorazmnozhenie-rastenii

Lomtatidze N., Zarnadze N., Alasania N., Zarnadze R. (2009). "In Vitro Morphogenesis of Loquat (Eriobotria japonica L.).” Bulletion of the Georgian National Academy of Sciences, 3(1), 123-125.

https://www.yumpu.com/en/document/view/26123955/eriobotria-japonica-1-the-georgian-national-academy-of-sciences

Maharik N., Elgengaihi S., Taha H. (2009). In vitro Mass Propagation of the Endangered Sinai Hawthorn Crataegus Sinaica Boiss. International Journal of Academic Research, 1(1). September, 23-29.

https://www.researchgate.net/publication/46391909_In_vitro_mass_propagation_of_the_endangered_sinai_hawthorn_cratae gus_sinaica_boiss

Mahoney J.D., Apicella P.V., Brand M.H. (2018). Adventitious Shoot Regeneration from in vitro Leaves of Aronia Mitschurinii and Cotyledons of Closely Related Pyrinae taxa. Scientia Horticulturae, 237(14), 135-14. https://www.sciencedirect.com/science/article/pii/S0304423818302383

Murashige T., Skoog F. - A revised medium for rapid growth and bioassay with tobacco tissue cultures. Physiol. Plant. 15: 473 - 497. (1962). https://onlinelibrary.wiley.com/doi/abs/10.1111/j.1399-3054.1962.tb08052.x

Nas M.N., Gokbunar L., Sevgin N., Aydemir M., Dagli M. (2012). Micropropagation of mature Crataegus Aronia L.a Medicinal and Ornamental Plant with Rootstock Potential for Pome Fruit. Plant Growth Regulation, 67, 57-63. https://link.springer.com/article/10.1007/s10725-012-9662-x

Rajpriay P., Singh K., Jaiswal N., Lall R. (2018). Optimizing the Effect of Plant Growth Regulators o in Vitro Micro Propagation of Indian Red Banana (Musa Acuminata). Journal of Pharmacognosy and Phytochemistry, 1, 628-634. http://www.phytojournal.com/archives/2018/vol7issue1S/PartJ/SP-7-1-347-586.pdf 
Siddique I., Javed S.B., Anis M. (2013). Stimulation of in vitro Organogenesis from Epicotyl Explants and Successive Micropropagation Round in Cassia angustifolia Vahl.: an Important Source of Sennosides. Agroforestry Systems, 87(3), 583590. https://link.springer.com/article/10.1007/s10457-012-9578-5

Stevens M.E., Pijut P.M. (2018). Rapid in vitro Shoot Multiplication of the Recalcitrant Species Juglans Nigra L. In Vitro Cellular \& Developmental Biology - Plant, 54, 309-317. https://link.springer.com/article/10.1007/s11627-018-9892-3

Wowtosh C., Prinz S., Soleiman Y., Koop B. (2007). Clonal propagation of Crataegus Monogina Jacq. (Lindm). Planta Medica, 73, 617. https://www.thieme-connect.com/products/ejournals/abstract/10.1055/s-2007-987397

Zarnadze N., Diasamidze I., Varshanidze N., Dolidze K., Bolkvadze T. (2018). In vitro Reproduction of Kidney Tea (Orthosiphon stamineus Bents). Journal of Pharmacy and Pharmacology, 6, 695-699. https://www.davidpublisher.org/Public/uploads/Contribute/5b39a180e6ca0.pdf

Zarnadze N., Dolidze K., Manjgaladze S., Bolkvadze T., Diasamidze I. (2019). Somatic Embryogenesis in Hyacinth in-vitro Culture. International Journal of Biotechnology and Recent Advances, 2019, 2(1), 57-59. https://madridge.org/journal-ofbiotechnology-and-recent-advances/ijbr-1000109.php 